\title{
Sienijuuri vähentää mansikan fosforilannoitustarvetta
}

Kati Hoppula ${ }^{1)}$, Anu Räty ${ }^{1)}$, Kalle Hoppula ${ }^{1)}$, Juho Hautsalo ${ }^{2)}$ Janne Ylijoki $^{1)}$, Jukka Kemppainen ${ }^{1)}$ ja Mauritz Vestberg ${ }^{2)}$

${ }^{1)}$ Luke Sotkamo, Kipinäntie 16, 88600 Sotkamo, etunimi.sukunimi@luke.fi

2)Luke Laukaa, Antinniementie 1, 41330 Vihtavuori, etunimi.sukunimi@luke.fi

Sienijuuriymppäys keinotekoiseen kasvualustaan sekä peltomaan luontainen sienijuuri edistivät merkitsevästi mansikan kasvua alhaisilla fosforitasoilla astiakokeissa. Myös peltokokeissa mansikka sai sienijuurisymbioosin avulla fosforiköyhästä, karkeasta kivennäismaasta riittävän määrän fosforia, jotta kykeni täysipainoiseen kasvuun ja sadontuottoon ilman fosforilannoitusta kolmen viljelyvuoden aikana.

Luke Sotkamon kolmivuotinen peltokoe perustettiin fosforiköyhälle lohkolle (mHe / mhsHHt) vuonna 2014. Fosforipitoisuus ennen lannoitusta oli keskimäärin 3,1 $\mathrm{mg} \mathrm{l}^{-1}$. Fosforilannoitus annettiin pitoisuuksilla 30/15, 60/30 ja 90/45 $\mathrm{kg} \mathrm{P} \mathrm{ha}^{-1}$, joista ensimmäinen vuosi rakeisena ja muut vuodet nestemäisenä. P0 kontrollina toimi fosforilannoittamaton peltomaa.

Luke Laukaan kaksivuotisessa astiakokeessa vuonna 2014 käytettiin kasvualustaseosta, jonka fosforipitoisuus ennen lannoitusta oli $0 \mathrm{mg} \mathrm{l}^{-1}$. Muut fosforitasot olivat 10, 20, $30 \mathrm{ja} 50 \mathrm{mg} \mathrm{l}^{-1}$. Kasvualustalle tehtiin ymppäyskäsittely (Myko-Ymppi ${ }^{\circledR}$ ) ja kontrollina toimi ymppäämätön kasvualusta. Vuonna 2015 käytettiin luontaista sienijuurta sisältävää peltomaata (mhsHHt), jonka fosforipitoisuus oli 4,9 mg $\mathrm{l}^{-1}$. Muut fosforitasot olivat 10, $20 \mathrm{ja} 40 \mathrm{mg} \mathrm{l}^{-1}$. Kontrollina toimi höyrytetty peltomaa. Muiden ravinteiden riittävä saanti turvattiin pelto- ja astiakokeissa lannoittein. Koetaimina käytettiin mikrolisättyä, jatkuvasatoista Ria-lajiketta, joka tuotti jo istutusvuonna satoa.

Fosforilannoitus ei vaikuttanut myönteisesti peltokokeen sadontuottoon. Lannoittamattomaan kontrollikäsittelyyn nähden fosforilannoituskäsittelyt tuottivat tilastollisesti analysoituna joko heikomman tai yhtä suuren sadon. Istutusvuonna mansikka näytti lisäksi hyötyvän alhaisesta fosforipitoisuudesta tuottamalla enemmän juuri- ja lehtimassaa kuin runsaan fosforilannoituksen saaneet taimet. Sienijuuren kolonisaatioanalyysit osoittivat, että edellytykset mansikan sienijuurisymbioosiin olivat olemassa kaikilla peltokokeen lannoitustasoilla jo istutusvuonna.

Astiakokeiden turvepohjaisessa kasvualustassa fosforilannoitus $20 \mathrm{mg} \mathrm{l}^{-1}$ toi parhaan sadon eikä sienijuuren lisäyksellä ollut merkitsevää vaikutusta. Sienijuurta sisältävässä peltomaassa fosforipitoisuus 5 $\mathrm{mg} \mathrm{l}^{-1}$ riitti kuitenkin tuottamaan muita käsittelyjä vastaavan sadon. Sienijuuri edisti mansikan kasvua alhaisilla fosforitasoilla kasvualustasta riippumatta. Sienijuurettomat mansikat jäivät kuivapainoltaan selvästi muita heikommiksi, kun fosforia oli vähän tarjolla. Sienijuuri aikaisti myös kukinnan alkua ja voimisti rönsyntuottoa.

Tutkimus oli osa Makeran rahoittamaa Vihannesten ja marjakasvien tasapainoinen N- ja P-lannoitus ja ravinnepäästöjen vähentäminen -hanketta

Asiasanat: fosforilannoitus, mansikka, sienijuurisymbioosi 


\section{Johdanto}

Fosforilannoitussuositukset perustuvat Suomessa maaperän viljavuusanalyysin liukoisen fosforin pitoisuuteen. Niissä ei ole huomioitu maan mikrobitoimintaa, jolla on huomattava merkitys mansikan fosforitalouteen (Holevas 1966, Vestberg 1995, Vestberg ym. 2002). Monissa Euroopan maissa yleisesti käytössä olevaa lehtianalyysia ei Suomessa juurikaan hyödynnetä.

Mansikan fosforilannoitusta ohjaa voimakkaasti maatalouden ympäristökorvaus, johon suurin osa Suomen maatiloista on sitoutunut. Ympäristökorvauksessa mansikan fosforilannoituksen maksimitasot on määritelty viljavuusanalyysin perusteella viljavuusluokittain välille $0-60 \mathrm{~kg} \mathrm{ha}^{-1}$ perustamisvuoden kasvustolle ja satovuosina välille $0-35 \mathrm{~kg} \mathrm{ha}^{-1}$. Lisäksi tihkukastellulla mansikalla on sallittua lisätä maksimifosforilannoitusta 0,4 kg jokaista $1000 \mathrm{~kg}$ kohden satotason ylittäessä $10000 \mathrm{~kg} \mathrm{ha}^{-1}$. Mansikan viljelyn oppikirjassa (Matala 2006) lannoitussuositukset ovat kuitenkin ympäristökorvauksen maksimitasoja selvästi alempana.

Mansikka ottaa tarvitsemansa fosforin suoraan juurillaan tai epäsuorasti sienijuuririhmaston kautta. Jälkimmäinen strategia on vallitseva, kun fosforia on niukasti saatavilla. Mansikka muodostaa myös herkästi sienijuurisymbioosin ja ylläpitää tehokkaita keräsieniyhteisöjä maassa (Vestberg ym. 2005). Mansikka hyötyy tunnetusti sienijuuresta alhaisella lannoitustasolla (Holevas 1966, Daft ja Okusanya 1973). Korkealla fosforitasolla sienijuurisymbioosi toimii kasveilla heikosti ja voi jopa heikentää symbioottisten kasvien kasvua (Kahiluoto ym. 2001). Maan fosforipitoisuuden ollessa korkea kasvi ottaa fosforinsa suurimmaksi osaksi juurten kautta. Mansikalla on suuri fosforintarve kukkimisen ja sadonmuodostuksen välillä, jonka tyydyttämiseksi mansikan oma juuristo ei riitä vaan siihen tarvitaan myös sienijuuren apua (Dunne ja Fitter 1989). On näyttöä myös korkealla lannoitustasolla saaduista hyödyistä (Plenchette ym. 1982, Stewart ym. 2005), mutta sitä, miten sienijuuri vaikuttaa mansikan fosforilannoitusvasteeseen, ei Suomen olosuhteissa ole selvitetty.

Tarpeenmukainen fosforilannoitus on perusteltua sekä hyvän kasvun, viljelyn taloudellisuuden että ympäristövaikutusten kannalta. Maatilatalouden Kehittämisrahaston (MAKERA) rahoittama ja Luonnonvarakeskuksen (Luke) toteuttama Vihannesten ja marjakasvien tasapainoinen $\mathrm{N}$ - ja P- lannoitus ja ravinnepäästöjen vähentäminen -hanke (PuutarhaNP) selvitti vuosina 2014-2016 fosforilannoituksen vaikutuksia puutarhakasvien kasvuun ja sadontuottoon Suomessa. Luonnonvarakeskuksen toimipisteissä Sotkamossa ja Laukaassa selvitettiin fosforilannoituksen vaikutusta mansikan sienijuurisymbioosiin sekä kasvin kasvuun ja sadontuottoon. Tutkimuksen tavoitteena oli selvittää ovatko nykyiset ympäristötuen sallimat mansikan fosforilannoitusmäärät oikealla tasolla sadontuoton kannalta. Lisäksi tavoitteena oli selvittää voidaanko mansikan fosforilannoitusta vähentää sienijuuren avulla satotasoa heikentämättä. Hypoteesina oli, että alhaisella maan fosforintasolla mansikan fosforintarve tulee tyydytetyksi sienijuurisymbioosin avulla.

\section{Materiaalit ja menetelmät}

Luke Sotkamon toimipisteen pellolle (maalaji mHe / mhsHHt) perustettiin vuonna 2014 kolmivuotinen peltokoe. Laukaan toimipisteellä perustettiin astiakokeet kausihuoneeseen vuosina 2014 ja 2015 . Kokeissa käytettiin mikrolisättyä, jatkuvasatoista Ria-lajiketta, joka tuottaa jo istutusvuonna satoa. Sotkamon peltokokeen fosforipitoisuus ennen lannoitusta oli keskimäärin $3,1 \mathrm{mg} \mathrm{l}^{-1}$ maata eli viljavuusanalyysin mukaan huononlainen. Peltokokeen taimet istutettiin paririviin mansikkamuoviin ja kasteltiin tihkukastelulla. Peltokokeessa oli neljä lannoituskäsittelyä ja neljä kerrannetta. Astiakokeissa oli vuonna 2014 viisi lannoitustasoa, kaksi sienijuurikäsittelyä ja kymmenen kerrannetta ja vuonna 2015 neljä lannoituskäsittelyä, kaksi sienijuurikäsittelyä ja kymmenen kerrannetta.

Sotkamon koetta perustettaessa annettiin 2014 neljä erilaista rakeista fosforilannoituskäsittelyä: 0, 30, 60 ja $90 \mathrm{~kg} \mathrm{ha}^{-1}$. Vuosina 2015 ja 2016 fosforilannoitustasot 0, 15, 30 ja $45 \mathrm{~kg} \mathrm{ha}^{-1}$ ylläpidettiin tihkukastelun kautta nestemäisellä lannoitteella. Jatkossa tekstissä viitataan eri fosforilannoitustasoihin seuraavasti: käsittely, joka sai perustamislannoituksena $30 \mathrm{~kg} \mathrm{P} \mathrm{ha}^{1}$ ja kastelulannoituksena $15 \mathrm{~kg} \mathrm{P} \mathrm{ha}^{-1}$ on käsittely P30/15 jne. Vuoden 2014 Laukaan astiakokeessa fosforipitoisuudet olivat 0, 10, 20, 30 ja 50 $\mathrm{mg} \mathrm{l}^{-1}$ ja litran ruukuissa kasvualustana oli seos, jossa oli höyrytettyä hiekkaa, höyrytettyä tummaa turvetta (lisätty dolomiittikalkkia $10 \mathrm{~g} \mathrm{l}^{-1}$ maata) ja perliittiä (1:1:1). Vuonna 2015 astiakoe toteutettiin kahden litran ruukuissa käyttäen kasvualustana peltomaata (mhsHHt), jonka viljavuusfosforipitoisuus 
oli 4,9 $\mathrm{mg} \mathrm{l}^{-1}$ eli huononlainen. Fosforilannoituksella muodostettiin lähtötason lisäksi kolme korkeampaa fosforitasoa: 10, $20 \mathrm{ja} 40 \mathrm{mg} \mathrm{l}^{-1}$. Astiakokeissa vuonna 2014 kasvualustalle tehtiin ymppäyskäsittely (Myko-Ymppi ${ }^{\circledR}$ ) ja kontrollina toimi ymppäämätön kasvualusta. Vuonna 2015 astiakokeessa käytettiin peltomaata ja luontaista sienijuurta. Luontainen sienijuuri hävitettiin peltomaasta höyryttämällä, ja kontrollina toimi höyryttämätön, todistetusti sienijuurta sisältävä peltomaa. Muiden ravinteiden saanti turvattiin kaikissa pelto- ja astiakokeissa lannoittein.

Astia- ja peltokokeista mitattiin mansikan kasvua ja satoisuutta sekä sienijuurikolonisaatiota mansikan juurissa. Peltokokeesta satoa kerättiin elo-syyskuun vaihteeseen saakka. Kolonisaation määritystä varten peltokokeesta kerättiin näytteitä heinäkuussa sekä elokuun ja syyskuun vaihteessa, paitsi vuonna 2014, jolloin kerättiin vain yksi näyte elokuun lopulla. Kenttäkokeesta kerättiin myös kasvinäytteitä, joista määritettiin kasvinosittain tuore- ja kuivapainot, kivennäiset sekä kuiva-ainepitoisuudet. Maa- ja kasvinäytteet analysoitiin kivennäisten osalta Eurofins Viljavuuspalvelu Oy:n laboratorioissa. Astiakokeissa satoa kerättiin kokeen loppuun saakka (elo-syyskuun vaihde). Juurinäytteet kerättiin astiakokeista kasvatuksen päätteeksi. Peltokokeessa mansikan juuret säilöttiin laimennettuun alkoholiliuokseen (1:1, vesi: etanoli 96.1\%) ja värjättiin metyyli-sinivärjäyksellä (Phillips ja Hayman 1970). Kolonisaatio arvioitiin näytteistä grid-line intersect -menetelmällä (Giovannetti ja Mosse 1980). Astiakokeiden juurinäytteet käsiteltiin samalla menetelmällä, mutta ilman alkoholi-vesi-säilytystä. Tulosten luotettavuus on testattu varianssianalyysien ja t-testien avulla (SAS EG, versio 5.1), paitsi mansikan kivennäisaineiden sekä tuore- ja kuivapainojen tulokset. Kivennäisaineille sekä tuore- ja kuivapainoille ei kyetty osoittamaan tilastollisesti merkitseviä eroja liian pienen aineiston vuoksi. Tilastollisen merkitsevyyden raja-arvona käytettiin 5\% riskiä.

\section{Tulokset}

Alhainen fosforitaso ei heikentänyt mansikan kasvua tai sadontuottoa kolmivuotisen viljelyjakson aikana Sotkamon peltokokeissa. Tilastollisesti merkitsevää eroa mansikan satotasossa ei havaittu matalimman P0 fosforilannoitustason ja korkeimman P90/45 lannoitustason välillä yhtenäkään vuonna (Kuva 1). Ainoat tilastollisesti merkitsevät erot syntyivät vuonna 2015 käsittelyjen P0 ja 30/P15 sekä P30/15 ja P60/30 välille, jolloin P30/15 käsittely tuotti keskimäärin muita heikomman sadon. Seuraavana vuonna satoerot eivät olleet tilastollisesti merkitseviä, vaikka käsittely P30/15 tuotti jälleen keskimääräisesti muita heikomman sadon.

Sienijuurikolonisaatioprosentti oli keskimäärin korkeampi alemmilla fosforitasoilla ja matalampi korkeammilla fosforitasoilla (Kuva 2). Poikkeuksena peltokokeen perustamisvuosi 2014, jolloin sieni-juurikolonisaatioprosentit eivät poikenneet toisistaan tilastollisesti merkitsevästi.

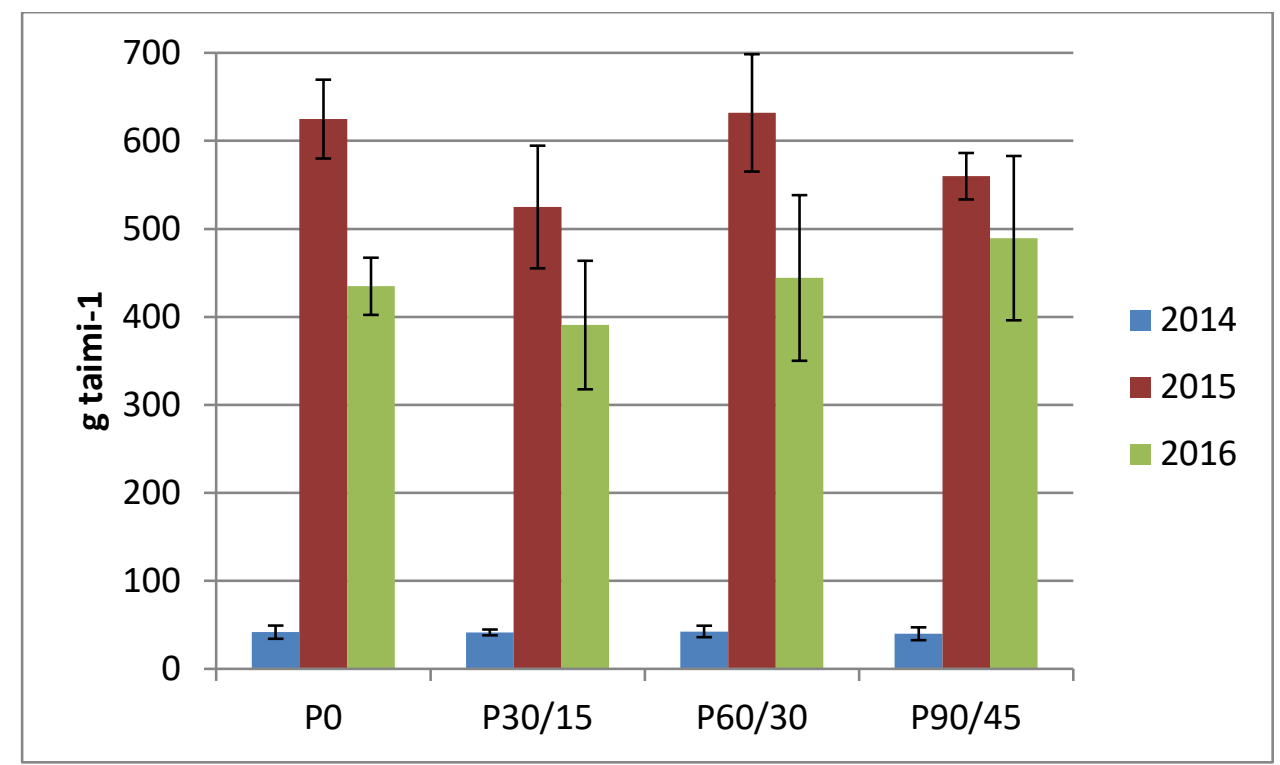

Kuva 1. Mansikan keskimääräinen satotaso $\left(\mathrm{g} \mathrm{taimi}^{-1}\right)$ eri fosforilannoitustasoilla $\left(\mathrm{kg} \mathrm{ha}^{-1}\right)$ Sotkamon peltokokeissa vuosina 2014-2016. 


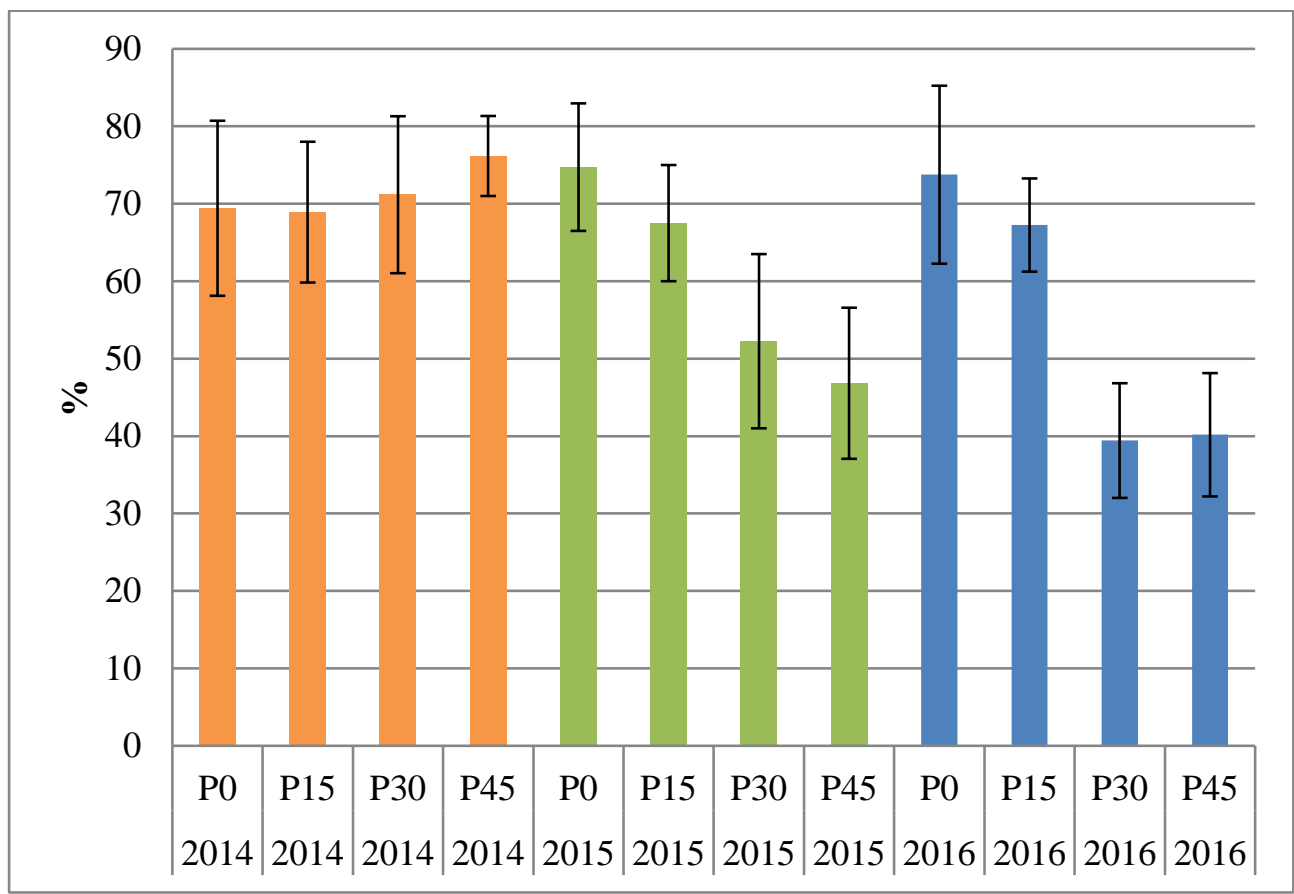

Kuva 2. Mansikan sienijuurikolonisaatiot (\%) loppukesän näytteissä, vuosina 2014-2016 Sotkamon peltokokeissa.

Mansikan ravinneanalyysit tehtiin vuosina 2015-2016. Analyysien mukaan mansikka otti fosforia enemmän, kun sitä oli helposti saatavilla eli fosforipitoisuudet eri kasvinosissa nousivat fosforilannoituksen lisääntyessä. Fosforilannoitus ei kuitenkaan huomattavasti lisännyt keskimääräistä kasvin fosforinottoa. Laskennallisesti koealalta mansikkasadon mukana poistui fosforia noin 5,5-7,0 $\mathrm{kg} \mathrm{ha}^{-1}$ eli satoon suhteutettuna $0,4 \mathrm{~kg}$ jokaista tuhatta satokiloa kohden.

Istutusvuonna mansikka näytti hyötyvän alhaisesta fosforilannoituksesta, sillä mansikan juurten, lehtien ja kukkavanojen tuoremassa oli keskimäärin muita suurempi käsittelyissä P0 ja P30/15. Kasvuunlähtö kaikissa lannoituskäsittelyissä oli kuitenkin tasaista. Vuosina 2015-2016 kukkavarsien kuivapaino oli suurin käsittelyssä P0. Vuonna 2015 käsittelyn P30/15 heikko sato näkyi myös alhaisina kuivapainoina eri kasvinosissa. Vuonna 2016 käsittely P30/15 poikkesi muista enää runsaampana rönsyntuottona ja hieman heikompana marjojen kuivamassana.

Seurantajaksolla vuosina 2014-2016 peltomaan viljavuusanalyysin fosforipitoisuus nousi kaikissa lannoituskäsittelyissä, jopa nollaruudussa (Taulukko 1). Suurimmat kertymät olivat käsittelyssä P60/30, jossa maan fosforipitoisuus nousi lähtötasosta 2,3 $\mathrm{mg} \mathrm{l}^{-1}$ ja käsittelyssä P90/45, jossa nousua oli 4,8 mg $\mathrm{l}^{-1}$. Varastofosforin määrä koealueella vaihteli kokeen alussa $296-362 \mathrm{mg} \mathrm{l}^{-1}$, mikä vastaa $25 \mathrm{~cm}$ pintakerroksessa $740-905 \mathrm{~kg}$ fosforia hehtaarille. Tämä vastaisi $5000 \mathrm{~kg} \mathrm{ha}^{-1}$ mansikkasadolla noin 150-200 vuoden mansikan fosforitarvetta.

Taulukko 1. Maan viljavuusanalyysin fosforipitoisuus (mg l-1) Sotkamossa eri lannoituskäsittelyissä vuosina 2014-2016. Lähtötaso on vuonna 2014.

\begin{tabular}{llll}
\hline Fosforilannoituskäsittely kg ha ${ }^{-1}$ & 2014 & 2015 & 2016 \\
\hline 0 & 3,0 & 3,4 & 3,2 \\
$30 / 15$ & 3,4 & 4,2 & 4,0 \\
$60 / 30$ & 3,1 & 5,0 & 5,4 \\
$90 / 45$ & 3,0 & 5,6 & 7,8 \\
\hline
\end{tabular}

Laukaan astiakokeissa sienijuurikäsittely ei lisännyt merkitsevästi mansikan satoa, mutta alhaisessa fosforissa ilman sienijuurta kasvaneet mansikat jäivät kuivapainoltaan selvästi muita heikommiksi (Kuva 
3). Sienijuurisymbioosi aikaisti myös kukinnan alkua ja voimisti rönsyntuottoa. Taimien kukka-aiheita ei kuitenkaan laskettu, joten seuraavan vuoden satopotentiaalia ei pystytty arvioimaan.

Vuoden 2014 astiakokeiden turvepohjaisessa kasvualustassa fosforilannoitus toi parhaan sadon $20 \mathrm{mg}$ $\mathrm{l}^{-1}$ fosforipitoisuudessa. Vuonna 2015 sienijuurta sisältävässä peltomaassa vastaavaan satoon riitti kuitenkin jo fosforipitoisuus $5 \mathrm{mg} \mathrm{l}^{-1} .20 \mathrm{mg} \mathrm{l}^{-1}$ suuremmat fosforitasot kasvattivat mansikan vegetatiivista massaa. Sienijuurelliset mansikat erosivat kasvultaan sienijuurettomista, ja alhaisilla lannoitustasoilla sienijuuren kasvua edistävä vaikutus oli selvä. Vaikutus lakkasi kuitenkin näkymästä jo kohtalaisen lannoituksen myötä. Sienijuuresta riippumatta korkeampi fosforilannoitus tasasi kasvun eroja ja korkeimmat fosforitasot suosivat vegetatiivista kasvua marjonnan sijaan.

Maan höyrytys vaikutti todennäköisesti mansikan käytössä olevien typpivarojen määrään ja se saattaa selittää paremman kasvun $40 \mathrm{mg} \mathrm{l}^{-1} \mathrm{P}$ tasolla.

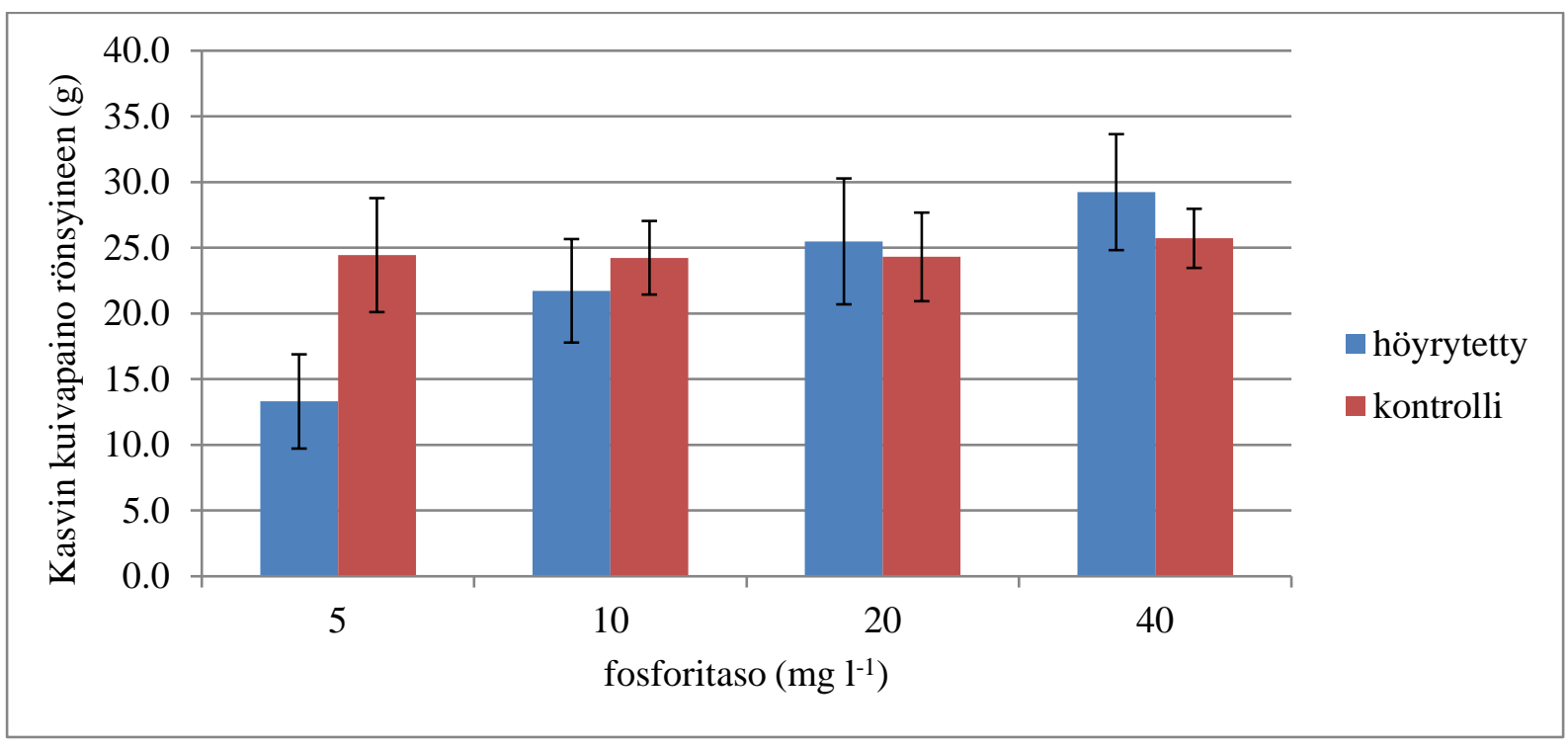

Kuva 3. Mansikan koko kasvin keskimääräinen kuivapaino ja keskihajonnat eri fosforitasoilla peltomaalla tehdyssä astiakokeessa vuonna 2015. Kontrolli sisältää luontaisen sienijuuren ja höyrytetyssä käsittelyssä sienijuuri deaktivoitiin peltomaasta.

\section{Tulosten tarkastelu}

Aiempien tutkimusten pohjalta tiedettiin mansikan sienijuurisymbioosin olevan voimakas (Vestberg ym. 2005) ja edistävän fosforin ottoa etenkin alhaisilla fosforitasoilla (Holevas 1966, Daft ja Okusanya 1973). Astiakokeiden tulokset tukevat havaintoa, sillä niissä sienijuuriymppäys keinotekoiseen kasvualustaan sekä peltomaan luontainen sienijuuri edistivät molemmat merkitsevästi mansikan kasvua alhaisilla fosforitasoilla. Myös peltokokeista saadut tulokset vahvistavat aiempia havaintoja. Kolmen viljelyvuoden aikana mansikka sai symbioosin avulla fosforiköyhästä, karkeasta kivennäismaasta riittävän määrän fosforia, jotta kykeni täysipainoiseen kasvuun ja sadontuottoon.

Kolonisaatioanalyysit osoittivat, että edellytys symbioosiin oli mansikalla olemassa kaikilla peltokokeen lannoitustasoilla jo istutusvuonna. Symbioosi pysyi juurissa läpi koko kokeen myös runsasfosforisissa käsittelyissä. Symbioosin hyöty näkyi kuitenkin vain fosforilla lannoittamattomassa käsittelyssä, jossa sadontuotto oli yhtä suurta tai suurempaa kuin runsaasti lannoitetuissa käsittelyissä. Symbioosin toimiessa fosfori ei ollut kasvun minimitekijä edes alhaisessa maan fosforipitoisuudessa.

Runsaan fosforilannoituksen on kuitenkin todettu häiritsevän sienijuurisymbioosin toimintaa ja muuttavan sen jopa haitalliseksi (Kahiluoto ym. 2001, Vestberg ym. 2002). Biermannin ja Lindermannin (1983) keinotekoisilla kasvualustoilla tekemässä tutkimuksessa maanesteen fosforipitoisuus $5 \mathrm{mg} \mathrm{l}^{-1}$ vaikutti jo sienijuuren kautta tapahtuvaan fosforinottoon ja sienijuuren tuomaan hyötyyn negatiivisesti. Tämä tukee vuonna 2015 havaittua trendiä, jossa lannoitustaso P30/15 tuotti heikoimman kuivapainon 
ja satotuloksen. Käsittelyyn lisätty fosforimäärä $30 \mathrm{~kg} \mathrm{ha}^{-1}$ perustamisvuonna vastasi fosforipitoisuutta $12 \mathrm{mg} \mathrm{l}^{-1}$ ja satovuosina lisätyt $15 \mathrm{~kg} \mathrm{ha}^{-1}$ fosforia vastasi pitoisuutta $6 \mathrm{mg} \mathrm{l}^{-1}$.

Perustamisvuonna lannoitus annettiin mansikkakasvustoille rakeisena ja vuosina 2015-2016 nestemäisenä, mikä saattoi vaikuttaa sienijuuren toimintaan. Kasvit ottavat fosforia joko suoraan maasta juurien kautta tai sienijuurisymbioosin avulla. Fosforin suoraottoa tapahtuu pääasiassa juuren kasvavan kärjen tuntumassa, jossa fosforia on paljon vapaana. Sienijuurisymbioosi vallitsee vanhemmassa juurisolukossa (Smith ym. 2011). Nestemäinen fosforilannoite leviää maanesteessä rakeista lannoitetta tehokkaammin ja todennäköisesti tuo fosforia myös niukkafosforiselle alueelle lähelle vanhan juuren pintaa. Tomaatilla on huomattu fosforin suoran oton kohoavan ja sienijuuren merkityksen pienenevän, kun fosforipitoisuus kasvaa (Nagy ym. 2009). Runsaan fosforilisäyksen on huomattu myös laskevan symbioottisten kasvien kolonisaatioita (Kahiluoto ym. 2001), mikä tukee tuloksiamme. Juurten kolonisaatiossa ei havaittu merkitseviä muutoksia rakeisen lannoituksen vuonna 2014, mutta vuosina 2015-2016 kolonisaatio laski selvästi, kun fosforilannoitus lisättiin nestemäisenä.

Silmämääräisesti kasvustoista ei havaittu eroa lannoituskäsittelyiden välillä. Etenkin istutusvuonna mansikka kuitenkin näytti hyötyvän alhaisesta fosforilannoituksesta tuottamalla enemmän juuri- ja lehtimassaa kuin runsaan fosforilannoituksen saaneet taimet. Mansikan kasvullisessa vaiheessa uusien juurten ja lehtien kasvu on voimakasta (Matala 2006), ja silloin ravinnetarve on suuri. Sienijuurisymbioosin avulla mansikka voi tehostaa fosforin lisäksi myös muiden ravinteiden ottoa ja turvata siten ravinteiden saannin voimakkaan kasvun aikana.

Mansikan fosforintarpeen on todettu olevan suurimmillaan kukinnan ja sadonmuodostuksen välillä. Fosforitarpeen tyydyttämiseksi mansikan oma juuristo ei riitä, vaan siihen tarvitaan sienijuuren apua (Dunne ja Fitter 1989). Astiakokeissa sienijuurisymbioosi aikaisti kukinnan alkua, mutta sadontuotto ei istutusvuonna kuitenkaan merkittävästi lisääntynyt. Kukka-aiheita ei astiakokeissa laskettu, joten seuraavan vuoden satopotentiaalia ei pystytty arvioimaan. Peltokokeissa symbioosi vaikutti sadon määrään ja todennäköisesti positiivisesti myös kukkamääriin, sillä fosforilla lannoittamaton käsittely tuotti suurimmat kukkavanojen tuore- ja kuivapainot kaikkina koevuosina.

Mansikka käyttää samanaikaisesti resursseja sekä sadon- että rönsyjentuottoon, vaikka rönsynkasvu on voimakkainta satokauden jälkeen (Matala 2006). Astiakokeissa sienijuurisymbioosi voimisti rönsyntuottoa. Peltokokeissa fosforilannoittamattomassa P0-käsittelyssä samanlaista ilmiötä ei havaittu.

MTT Piikkiössä vuosina 1998-2001 tehdyn lannoitustutkimuksen mukaan mansikka käyttää 1000 kg sadontuottoon keskimäärin 0,4 kg fosforia. Sadontuoton lisäksi muuhun kasvuun mansikalla tarvitaan fosforia $2-5 \mathrm{~kg} \mathrm{ha}^{-1}$ taimen koosta riippuen. Tiheällä istutuksella fosforintarve voi nousta välille $5-8 \mathrm{~kg}$ $\mathrm{ha}^{-1}$. Muuhun kasvuun tarvittava fosfori palaa kuitenkin maahan kasvinosien maatuessa syksyllä tai viimeistään viljelykierron päätteeksi, eikä sitä tarvitse korvata lannoituksella (Salo ja Pulkkinen 2001). Tuloksemme vahvistivat aiemmat laskelmat. Koealueen viljavuusanalyysin mukaan maan fosforivarastot olisivat olleet riittävän suuret mansikan fosforitarpeen tyydyttämiseksi useiksi vuosikymmeniksi eteenpäin. Runsas fosforilannoitus nosti maan keskimääräistä viljavuusfosforin pitoisuutta koealalla. Tämä osoittaa, että nykyiset ympäristökorvausehtojen fosforilannoitusrajat ovat liian korkeita suhteessa mansikan tarpeeseen. Nykyisten lannoitusrajojen mukaan koealueen peltomaahan olisi saanut lisätä fosforia perustamisvuonna $60 \mathrm{~kg} \mathrm{ha}^{-1}$ ja satovuosina $35 \mathrm{~kg} \mathrm{ha}^{-1}$.

\section{Johtopäätökset}

Saamiemme tulosten perusteella nykyisiä fosforilannoitussuosituksia tulisi tarkentaa ainakin mansikan osalta. Tulevissa mansikan fosforilannoitussuosituksissa olisi huomioitava sienijuurisymbioosin merkitys ja korjattava suosituksia nykytasosta alaspäin. Sadon mukana poistuvan ravinnemäärän ylittävästä fosforilannoituksesta ei ole mansikan viljelyssä hyötyä, ja peltoon kertyvä ylimääräinen fosfori lisää huuhtoutumisriskiä. Mansikan viljelyssä kivennäismailla viljavuusanalyysin fosforitaso olisi sienijuuren toiminnan kannalta optimaalinen alle $10 \mathrm{mg} \mathrm{l}^{-1}$ tasolla.

Sienijuurisymbioosi pitäisi huomioida viljelykierron suunnittelussa ja viljelykasvin valinnassa. Huomioon pitäisi ottaa myös maalajien väliset erot symbioosin toiminnassa, sillä esimerkiksi turpeessa symbioosi ei toimi. Fosforin lannoitustapaa tulisi myös tarkastella, sillä kastelulannoitteena annettu fosfori häiritsee sienijuuren toimintaa ja voi aiheuttaa sadonmenetyksiä. Sienijuurisymbioosillisissa maissa, 
joita kaikki suomalaiset kivennäismaat ovat, pitäisi enemmän kiinnittää huomiota maan luontaisen mikrobiston tilaan. Pelkän kemiallisen fosforilannoituksen sijaan voitaisiin parantaa maan nykyisten fosforivarojen hyödyntämistä ja siirtyä ylläpitämään pellon fosforitilaa mansikan viljelykierron välikasveilla, karjanlannalla ja muilla maan mikrobitoiminnalle myönteisillä toimenpiteillä.

Ennen kuin pystytään tekemään kasvilajikohtaisia tarkempia viljelysuosituksia, tarvittaisiin kuitenkin vielä lisää tutkimusta sienijuuren toiminnan kartoittamiseksi eri kasvilajeilla ja lajikkeilla sekä erilaisissa maaperä- ja ilmasto-olosuhteissa. Huonosti tunnistettuna ja väärien viljelytoimenpiteiden seurauksena symbioosin huono toimivuus voi rasittaa kasvia ja johtaa sadon alenemiseen.

\section{Kirjallisuusviitteet}

Biermann, B. \& Lindermann, R.G. 1983. Effect of container plant growth medium and fertilizer phosphorus on establishment and host growth response to vesicular-arbuscular mycorrhizae. Journal of the American Society for Horticultural Science 108: 962-971.

Daft, M.J. \& Okusanya, B.O. 1973. Effect of Endogone mycorrhiza on plant growth. VI. Influence of infection on the anatomy and reproductive development in four hosts. New Phytologist 72: 1333-1339.

Dunne, M.J. \& Fitter, A.H. 1989. The phosphorus budget of field-grown strawberry (Fragaria x ananassa cv Hapil) crop: evidence for a mycorrhizal contribution. Annales of Applied Biology 114: 185-193.

Giovannetti, M. \& Mosse, B. 1980. An evaluation of techniques for measuring vesicular arbscular mycorrhizal infection in roots. New Phytologist 84: 489-500.

Holevas, C.D. 1966. The effect of vesicular-arbuscular mycorrhiza on the uptake of soil phosphorus by strawberry (Fragaria sp. var. Cambridge favourite). Journal of Horticultural Science 41: 57-64.

Kahiluoto, H., Ketoja, E., Vestberg, M. \& Saarela, I. 2001. Promotion of AM utilization through reduced P fertilization 2. Field studies. Plant Soil 231: 65-79.

Matala, V. 2006. Mansikan viljely. Puutarhaliiton julkaisuja 340. $335 \mathrm{~s}$.

Nagy, R., Drissner, D., Amrhein, N., Jakobsen, I. \& Bucher, M. 2009. Mycorrhizal phosphate uptake pathway in tomato is phosphorus-repressible and transcriptionally regulated. New Phytology 181: 950-959.

Phillips, J.M. \& Hayman, D.S. 1970. Improved procedures for clearing and staining parasitic and vesicular arbuscular mycorrhixal fungi for rapid assessment of infection. Transactions of the British Mycological Society 55: 158-161.

Plenchette, C., Furlan, V. \& Fortin J.A. 1982. Effects of different endomycorrhizal fungi on five host plants grown on calcined montmorillonite clay. Journal of the American Society for Horticultural Science 107: 535538.

Salo, T. \& Pulkkinen, J. 2001. Mansikan fosforin ja kaliumin otto. Maatalouden tutkimuskeskuksen julkaisuja. Sarja A 91: 27-32.

Smith, S.E., Jakobsen, I., Grønlund, M. \& Smith, F. A. 2011. Roles of arbuscular mycorrhizas in plant phosphorus nutrition: interactions between pathways of phosphorus uptake in arbuscular mycorrhizal roots have important implications for understanding and manipulating plant phosphorus acquisition. Plant physiology 156: 1050-1057.

Stewart, L.I., Hamel, C., Hogue, R. \& Moutoglis, P. 2005. Response of strawberry to inoculation with arbuscular mycorrhizal fungi under very high soil phosphorus conditions. Mycorrhiza 15: 612-619.

Vestberg, M. 1995. Occurrence of some Glomales in Finland. Mycorrhiza 5: 329-336.

Vestberg, M., Kukkonen, S. \& Uosukainen, M. 2002. Occurrence and effectiveness of indigenous mycorrhiza of some strawberry fields in Finland. Acta horticulturae 567: 499-502.

Vestberg. M., Saari, K., Kukkonen, S. \& Hurme, T. 2005. Mycotrophy of crops in rotation and soil amendment with peat influence the abundance and effectiveness of indigenous arbuscular mycorrhizal fungi in field soil. Mycorrhiza 15: 447-458. 